\title{
Arnold-Chiari malformation type I
}

INSERM

\section{Source}

INSERM. (1999). Orphanet: an online rare disease and orphan drug data base. ArnoldChiari malformation type I. ORPHA:268882

Arnold-Chiari malformation type I is a central nervous system malformation characterized by caudal displacement of the cerebellar tonsils exceeding $5 \mathrm{~mm}$ below the foramen magnum with or without syring omyelia. Symptoms vary in onset and severity and include suboccipital headache, neck pain, vertigo, tinnitus, ocular symptoms (diplopia, blurred vision, photofobia, nystagmus), lower cranial nerve signs, cerebellar ataxia, and spasticity. Some affected individuals can be asymptomatic. 